\title{
Experimental Studies on Four Stroke Diesel Engine Fuelled with Tamarind Seed Oil as Potential Alternate Fuel for Sustainable Green Environment
}

\author{
V. Dhana Raju ${ }^{1,2^{*}}$, P. S. Kishore ${ }^{2}$, K. Yamini ${ }^{1}$ \\ ${ }^{1}$ Department of Mechanical Engineering, Lakireddy Bali Reddy College of Engineering, Mylavaram-521230, INDIA \\ ${ }^{2}$ Department of Mechanical Engineering, Andhra University, Visakhapatnam-530003, INDIA
}

*Corresponding Author: dhanaraju.v@1brce.ac.in

Citation: Dhana Raju, V., Kishore, P. S. and Yamini, K. (2018). Experimental Studies on Four Stroke Diesel Engine Fuelled with Tamarind Seed Oil as Potential Alternate Fuel for Sustainable Green Environment. European Journal of Sustainable Development Research, 2(1), 10. https://doi.org/10.20897/ejosdr/78489

Published: January 30, 2018

\begin{abstract}
The main objective of this present novel work is to investigate the performance, combustion and emission characteristics of biodiesel derived from the tamarind seed through the transesterification process as potential alternative feedstock for the diesel engine. The physio-chemical properties of tamarind seed methyl ester (TSME) were evaluated experimentally and compared with the base fuel. Test fuels were prepared in 3 concentrations such as B10 (10\% tamarind seed oil and 90\% diesel), B20 and B30.Experiments were conducted at a constant speed, the injection timing of $23^{\circ}$ crank angle and compression ratio 17.5:1 with varying load conditions to investigate the diesel engine characteristics. TSME 20 shown better thermal efficiency (34.41\%) over diesel which is $1.17 \%$ higher and also it produces lower emissions of CO, HC, and smoke opacity. N-Amyl alcohol (NAA) is used as a fuel additive for the optimum blend of TSME20; added in $5 \%$ and $10 \%$ concentration on the volume basis. From the analysis of experimental data, the use of fuel additives significantly reduces the smoke opacity by $29.49 \%$ for TSME20 NAA $10 \%$ blend in addition to the reduction of carbon monoxide and hydrocarbons emissions; however, the specific fuel consumption and the oxides of nitrogen were marginally increased.
\end{abstract}

Keywords: tamarind seed oil, N-Amyl alcohol, performance, combustion, emission

\section{INTRODUCTION}

The demand for energy increases globally at an alarming rate and it creates the energy crisis. In this concern, tamarind seed oil is considered as one of the promising fuel substitutes for diesel in diesel engines towards the green environment. Recent few years, Biodiesel has gained the global recognition as a renewable fuel for the compression ignition engines because of improved performance and lesser emissions. It is apparent that the selected biomass waste is a more promising feedstock for biofuel production. As the feedstock is available in large quantity in the world, the production of bio-oil is of great interest for pyrolysis study and is a novel matter of subject for future research. Kadera et al. (2013) conducted experiments on optimum extraction of tamarind seed oil from the tamarind seed through the fire tube heating transesterification process and concluded that tamarind seed oil as one of the suitable alternate fuel for diesel. Shameer and Ramesh (2017) examined the performance consequences of an eco-friendly substance on the diesel engine and concluded that up to $20 \%$ biodiesel blend showed the close behaviour of BTE, BSFC and tailpipe emissions with greater penalty of NOx when analysed with base fuel. Dhana Raju et al. (2016) conducted experiments on compression ignition engine with mahua seed oil as alternate feedstock and reported that the mahua seed bio-fuel blends shown enhanced BTE and lowered exhaust emissions when analyzed with conventional diesel. Biodiesels contain inherent oxygen content; better lubricity and 
higher Cetane are the main reason for the improvement in thermal efficiency with biodiesel. Shelke et al. (2016) reported on the use of cottonseed oil as biodiesel and concluded that the cottonseed biodiesel can be used in blended form as an alternative fuel in any diesel engine without any modification. Ashok et al. (2017) conducted a novel research on the production of biodiesel from lemon fruit rinds and concluded lemon peel biodiesel and its blends revealed better performance and lower emissions due to its lesser density and low boiling temperature. Moshin et al. (2014) reported that the biodiesel could be used directly in a diesel engine without any modifications as suitable eco-friendly fuel. Pali and Kumar (2016) reported the use of shorea robusta methyl ester as biodiesel and concluded that combustion study exposed in increasing trend in heat release rate and reduced ignition delay. Some researchers (Dhana Raju and Kishore, 2017; Yilmaz and Atmanli, 2017) also noticed that significant reductions in exhaust emissions such as carbon monoxide, hydrocarbons and smoke emissions with the use of biodiesel over the diesel fuel. This was mainly attributed due to presence of more oxygen and higher Cetane number of biodiesel. Agarwal et al. (2008) investigated the production of biodiesel using the pyrolysis was the optimum approach in higher yields of biodiesel with lower viscosity. Ashok et al. (2017) conducted a novel research on the production of biodiesel from lemon fruit rinds and concluded lemon peel biodiesel and its blends revealed better performance and lower emissions due to its lesser density and low boiling temperature. Researchers (Nagaraja et al., 2016; Kumar and Loganathan, 2014) examined the corn seed oil as biodiesel on diesel engine and they were concluded that the corn oil methyl ester $20 \%$ blend has the potential to utilize as an alternative fuel for $\mathrm{CI}$ engines with no mechanism alteration, and also from the emission analysis they were concluded that the hydrocarbon and carbon monoxide decreases. Theansuwan and Triratanasirichai (2011) reported about the extraction of biodiesel by using the transesterification process yields quality biodiesel in terms of fuel properties. $\mathrm{Li}$ et al. (2015) investigated the effects of ternary fuel blend on the emission and combustion characteristics and noticed that the superior spray characteristics \& better air-fuel mixture formation ability of n-Amyl alcohol content in the ternary blend yields in higher efficiency and lower exhaust emissions. Kumar et al. (2016) investigated the use of advanced oxygenated fuel additives to reduce the oxides of nitrogen and other emissions from the engine exhaust of diesel engine. It was found that for $15 \%$ DMC blend, oxides of nitrogen was reduced by $46.1 \%$ and $39.3 \%$ reduction of Nox for the $45 \%$ pentanol blend. Imdadul et al. (2017) investigated the different oxygenated fuel additives to reduce the SFC and the oxides of nitrogen with $70 \%$ diesel- $20 \%$ biodiesel- $10 \%$ pentanol ternary blend on single cylinder diesel engine and concluded that the addition of 1-pentanol as fuel additive to biodiesel blend shown marginal improvement in brake thermal efficiency and considerable reduction of smoke and the emissions. Dhana Raju and Kishore (2017) reported that higher brake thermal efficiency obtained for 10\% dimethyl carbonate addition to the tamarind seed methyl ester blend over diesel fuel. Yamini et al. (2017) examined the effect of fuel additive on biodiesel and found that significant reduction in Hydrocarbon and smoke emissions and enhanced oxides of nitrogen emissions along with the improved thermal efficiency of diesel engine. Dhanasekaran et al. (2017) conducted experimental work by using the restaurant yellow grease, n-pentanol and diesel as ternary blend showing the lower viscosity and density with the reduction in net energy content and noticed that the smoke intensity was decreased with the rise in 1-pentanol quantity in the ternary blended fuel. Wei et al. (2014) investigated the influence of various concentrations of pentanol/diesel blends on diesel engine performance and their outcomes indicated that the BSFC improved with more concentration of pentanol in diesel and also noticed that oxides of nitrogen were increased by $8 \%$ at maximum load condition. Harveer et al. (2015) reported the use of Sal methyl ester as the biodiesel feedstock in diesel engine and experimental results revealed that the brake thermal efficiency was decreased with all the biodiesel blends when analysed with diesel fuel.

From the experimental research studies suggested that, n-Amyl alcohol (NAA) or 1-pentanol as a better fuel additive which can be blended with biodiesel to enhance the engine performance and lower the exhaust emissions. Therefore, current study exploits the influence of tamarind seed oil methyl ester biodiesel blends and also the addition of NAA at $5 \%$ and $10 \%$ on the volume basis in $20 \%$ tamarind seed methyl ester biodiesel blend to investigate the compression ignition engine characteristics without any modifications.

\section{MATERIAL METHODS}

Tamarind tree or Tamarindus indica is mainly belongs to the place of Africa; however, it has been grown in Indian and other subcontinents from many years. Presently, India is the biggest supplier of tamarind fruit in the globe, which is popularly consumed for the various cuisines preparations. It was largely available in the states of Madhya Pradesh, Andhra Pradesh, Karnataka, west Bengal, and Tamilnadu. Tamarind seed is a by-product obtained from the processing of tamarind fruit. The tamarind seed used in the current investigation for the production of biodiesel were collected from locally available trees. It may contain the oil yield of $18-26 \%$. Tamarind seed oil was generally extracted by means of hexane over the tamarind seed. The different steps involved in tamarind seed biodiesel production is shown in Figure 1. It is a by-product of the commercial or non-commercial use of the tamarind for various purposes. Free fatty acid or oil comprise of 4.5-16.2\% of the total composition. It 


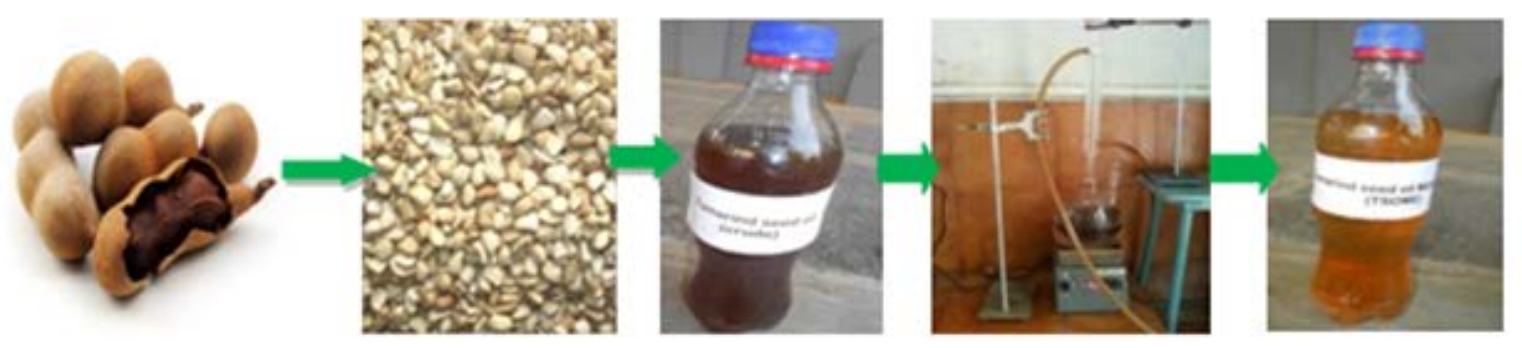

Tamarind fruit Tamarind seed Tamarind seed crude oil Tranaesterification Tamarind seed methyl enter

Figure 1. Various steps involved in Tamarind seed biodiesel production

Table 1. Properties of Diesel, Tamarind biodiesel blends and NAA

\begin{tabular}{lcccccc}
\hline Properties & Diesel & TSME & TSME10 & TSME20 & TSME30 & NAA \\
\hline Calorific value $(\mathrm{kJ} / \mathrm{kg})$ & 42,500 & 38,703 & 42,128 & 41,769 & 41,360 & 34,650 \\
\hline Specific gravity & 0.830 & 0.884 & 0.839 & 0.843 & 0.848 & 0.815 \\
\hline Kinematic viscosity $(\mathrm{cst})$ & 3.05 & 7.27 & 3.45 & 3.86 & 4.33 & 2.89 \\
\hline Flash point $\left({ }^{\circ} \mathrm{C}\right)$ & 56 & 159 & 66 & 74 & 86 & 49 \\
\hline Fire Point $\left({ }^{\circ} \mathrm{C}\right)$ & 63 & 170 & 74 & 83 & 96 & 54 \\
\hline Cetane number & 43 & 52.4 & 44 & 45 & 46 & 20
\end{tabular}

is having higher amounts of unsaturated fatty acids. Every year in India, the available tamarind seed is in the range of 2, 00,000-2, 50,000 tonnes was generated in tamarind fruit processing. From the dry seeds of tamarind, oil was obtained by means of solvent extraction technique. The physio-chemical properties of the biodiesel sample were determined experimentally and analysed with base fuel and presented in Table 1 . The heating value of tamarind seed oil was $92.5 \%$ on volume concentration of diesel.

\section{n-Amyl Alcohol as Fuel Additive}

In recent years the use of fuel additives with diesel and biodiesel blends are gaining interest to enhance the engine characteristics and rapid reductions in exhaust emissions. The variety of ignition improvers used by the researchers in their experimental works are Dimethyl carbonate ,Diethyl ether, Diethylene glycol, dimethyl ether , Di-n-butyl ether, Dimethoxymethane, Ethyl hexyl acetate ,Methyl tert-butyl ether , Ethylene glycol mono-n butyl ether , Dimethoxy propane ,methoxyethyl acetate ,Methanol and Ethanol. The fuel additives are mainly used to improve the fuel properties up to certain extent for various fuels due to more stable, low viscosity value, higher cetane value and rich inherent oxygen concentration produces the clean combustion of fuels in the engine cylinder and lower the tailpipe exhaust emissions. In this current experimental work, n-Amyl alcohol also known as 1pentanol $\left(\mathrm{C}_{5} \mathrm{H}_{12} \mathrm{O}_{2}\right)$ is chosen as the oxygenated fuel additive to the $20 \%$ tamarind seed methyl ester to know the engine characteristics and exhaust emissions.

\section{EXPERIMENTAL SETUP AND PROCEDURE}

The experiments were performed on kirloskar TAF1, 4-stroke, single cylinder vertical water cooled diesel engine at constant speed and for varying load conditions and it is shown in Figure 2. Necessary instruments were provided after inspection and calibration to estimate the engine parameters and exhaust emissions. The engine was run with diesel fuel to provide the baseline data, and then it was fuelled with different blends of TSME $(10 \%, 20 \%$, and $30 \%$ ) and finally for the optimum blend of TSME20, ignition improver as NAA (n-Amyl alcohol) was added at various concentrations $(5 \%$, and $10 \%)$ on volume basis. The detailed engine specifications are represented in Table 2. Under uniform steady conditions, the mass of fuel consumption rate, emission levels, pressure \& net heat generation at every crank angle were recorded.

AVL DI GAS 444N was employed to measure the exhaust emissions, AVL 437C smoke device was employed to gauge the concentration of intensity of smoke available in the engine tailpipe emissions. Combustion parameters were measured with AVL combustion analysis engine software. The pressure inside the cylinder and the heat produce rate were measured with AVL IC engine software. Various combustion thermal parameters of the diesel engine were recorded. The list of instruments and their range, accuracy and uncertainty are represented in Table 3. 


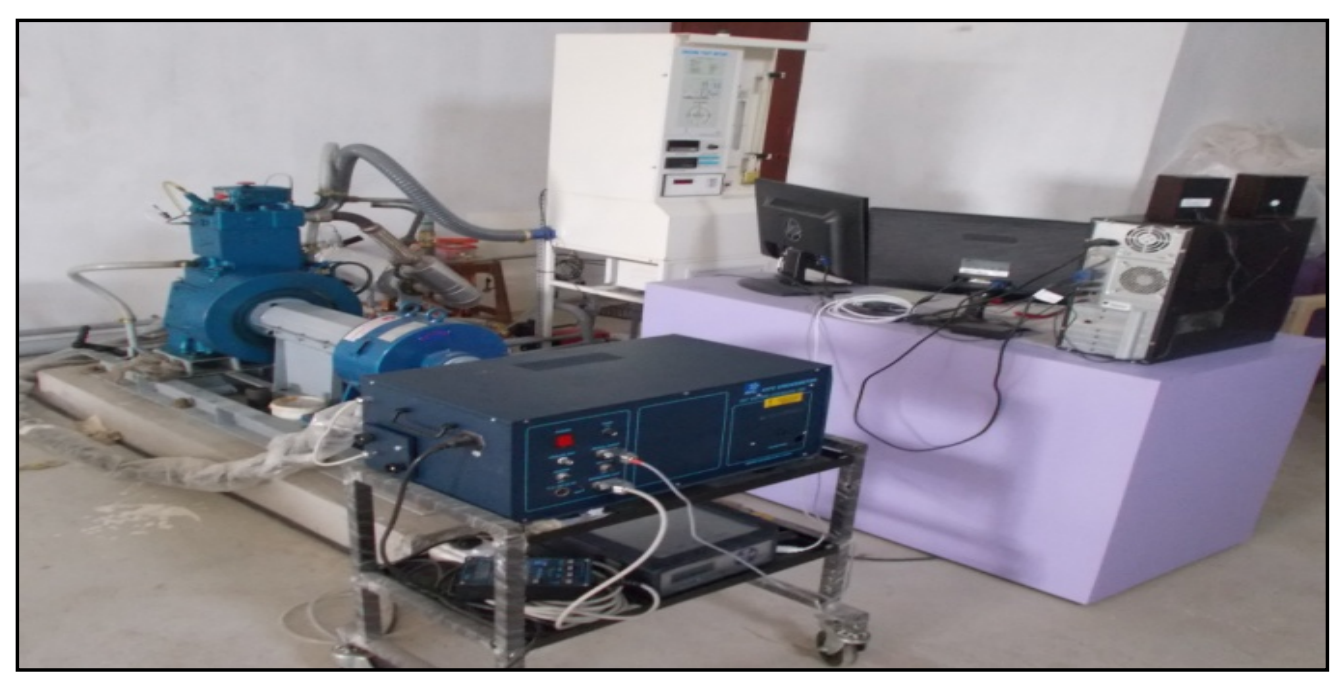

Figure 2. Shows the layout of kirloskar TAF1diesel engine set up

Table 2. Diesel engine specifications

\begin{tabular}{lc}
\hline Engine type & Kirloskar TAF1 four stroke, CI engine \\
\hline Rated power/speed & $5.2 \mathrm{~kW} / 1500 \mathrm{rpm}$ \\
\hline Cylinder bore & $87.5 \mathrm{~mm}$ \\
\hline Stroke & $110 \mathrm{~mm}$ \\
\hline Stroke volume & $661 \mathrm{CC}$ \\
\hline Compression Ratio & 17.5 \\
\hline No. of cylinders & 01 \\
\hline Inlet valve open before TDC & $4.5^{\circ}$ \\
\hline Inlet valve closes after BDC & $35.5^{\circ}$ \\
\hline Exhaust valve open before BDC & $35.5^{\circ}$ \\
\hline Exhaust valve closes after TDC & $4.5^{\circ}$ \\
\hline Fuel Injection timing bTDC & $23^{\circ}$ \\
\hline
\end{tabular}

Table 3. List of Instruments and their Range, Accuracy \& Uncertainties

\begin{tabular}{llccc}
\hline Instrument & Measurement & Range & Accuracy & Uncertainty \\
\hline \multirow{2}{*}{ AVL DI Gas 444 Five Gas Analyzer } & $\mathrm{CO}$ & 0 to $10 \%$ vol & $\pm 0.03 \%$ & $\pm 0.2 \%$ \\
& $\mathrm{CO} 2$ & 0 to $20 \%$ vol & $\pm 0.5 \%$ & $\pm 0.15 \%$ \\
\cline { 2 - 5 } & $\mathrm{HC}$ & 0 to $20000 \mathrm{ppm}$ & $\pm 10 \mathrm{ppm}$ & $\pm 0.2 \%$ \\
\hline AVL 415 Smoke Meter & $\mathrm{O}_{2}$ & 0 to $22 \% \mathrm{vol}$ & $\pm 0.1 \%$ & $\pm 0.5 \%$ \\
\hline AVL GH14d/AH1 Pressure transducer & PrN & 0 to $5000 \mathrm{ppm}$ & $\pm 50 \mathrm{ppm}$ & $\pm 1 \%$ \\
\hline AVL 365C Angle encoder & Crank angle & $0-99.9$ & $\pm 1 \%$ & $\pm 1 \%$ \\
\hline Data acquisition system & Combustion characteristics & $0-100 \mathrm{bar}$ & $\pm 0.1 \mathrm{bar}$ & $\pm 0.15 \%$ \\
\hline Temperature indicator & Temperature & $0-720^{\circ}$ & $\pm 1 \%$ & $\pm 0.2 \%$ \\
\hline
\end{tabular}

\section{RESULTS AND DISCUSSION}

The experiments were conducted on four stroke compression ignition diesel engine using different blends of biodiesel $(10 \%, 20 \%$ and 30\%) and diesel to estimate and analyze the engine characteristics at varying load conditions. Experimental outcomes revealed that $20 \%$ blend generates better engine characteristics which are favorably compared with that of diesel and also with other biodiesels. N-Amyl alcohol (NAA) was added to Tamarind seed methyl esters (TSME20) in different proportions (5\% and $10 \%$ on the volume basis) as ignition improver to know the effects on engine performance and emission characteristics as discussed below. Important engine performance parameters of TSME blends along with ignition improver addition were evaluated, analyzed and compared with diesel in the normal operating conditions of the diesel engine. 


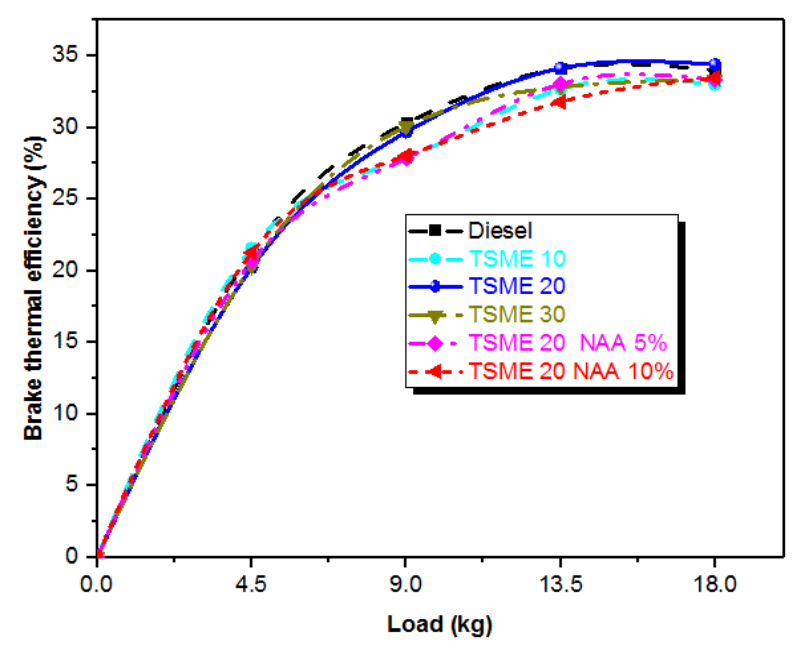

Figure 3. Brake thermal efficiency variation with load

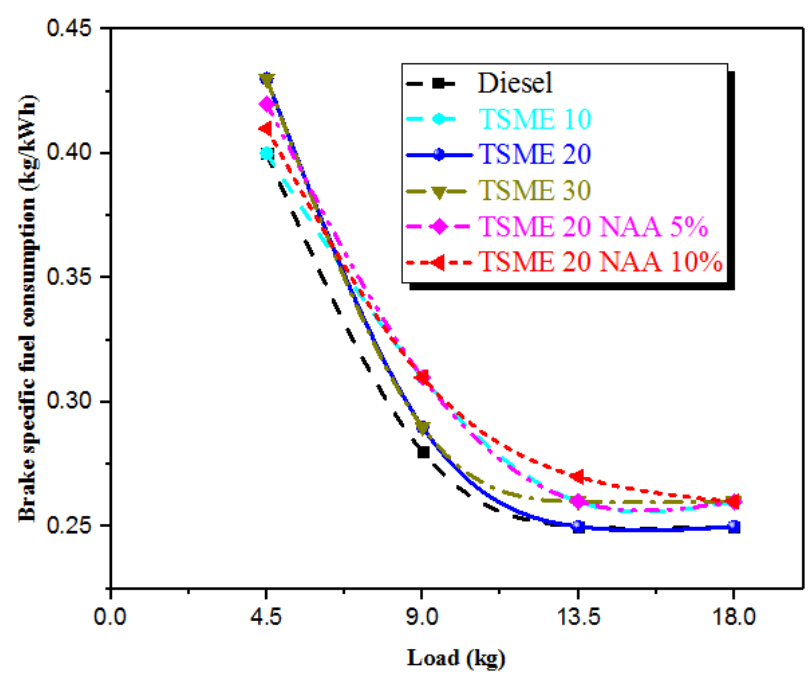

Figure 4. Brake specific fuel consumption variation with engine load

\section{Performance Characteristics}

\section{Brake Thermal Efficiency}

Figure 3 indicates the deviation of brake thermal efficiency (BTE) with the engine load for the tested fuels. The BTE for all tested tamarind seed oil and along with diesel fuel increases with increase in load and followed the same trend. The maximum brake thermal efficiency was observed for the TSME20 blend was $34.41 \%$ and for diesel was 34\%.TSME 20 biodiesel blend was 1.2\% higher thermal efficiency than base oil at peak load condition.NAA addition to TSME 20 at various concentrations indicates the slight reduction in BTE when compared with diesel and also with $20 \%$ biodiesel blend. The maximum brake thermal efficiency for TSME 20 NAA 5\% biodiesel was $33.65 \%$, which is $1.01 \%$ lower than the diesel fuel. The marginal decrease in brake thermal efficiency was mainly attributed due to the lower energy content of the n-Amyl alcohol. The authors (Das et al.. 2016) also reported that the performance and emission characteristics of castor oil were much closer to diesel and sometimes even better than base fuel.

\section{Brake Specific Fuel Consumption}

The variation of BSFC with engine load is shown in Figure 4. The specific fuel consumption of any fuel mainly depends on the heat energy content, density, and viscosity. The specific fuel consumption of tested biodiesels decreases with increases in load and found a minimum value at full load condition. The BSFC initially decreases sharply with an increase in load up to $50 \%$ and then decreases marginally with an increase in load; however, TSME 20 showed the least value of $0.25 \mathrm{~kg} / \mathrm{kWh}$. The addition of NAA as ignition improver results in better combustion leads to decrease the BSFC with the load as shown in Figure 5. The brake specific fuel consumption values were $0.252 \mathrm{~kg} / \mathrm{kWh}$ and $0.255 \mathrm{~kg} / \mathrm{kWh}$ for TSME20 5\% NAA, and TSME20 10\% NAA, and with diesel fuel it was $0.25 \mathrm{~kg} / \mathrm{kWh}$ at maximum load. The reason for the marginal increase in BSFC of TSME20 NAA biodiesel blends is mainly due to the lower heating value of NAA. It was concluded that the least value of BSFC for TSME20 blend was found to be $0.25 \mathrm{~kg} / \mathrm{kWh}$ which is similar to the pure diesel.

\section{Combustion Characteristics}

The combustion of a fuel is one of the vital aspects which are to be analyzed in a diesel engine, as it directly deals with the specific fuel consumption, thermal efficiency, and steadiness of an engine. The phenomenon of combustion in an engine was clearly analyzed with the help of Pressure-Crank angle diagram, Heat release rate and the delay period. Combustion parameters were measured with AVL Pressure transducer GH14d/AH1 fixed at Cylinder head and AVL 365C Angle encoder was fixed on the crankshaft of an engine. The Pressure of cylinder and heat generation was measured by using AVL engine software. The Mathematical equation was (1) developed by Heywood (1984) for the evaluation total heat release rate during combustion phenomenon according to the First law of Thermodynamics. 


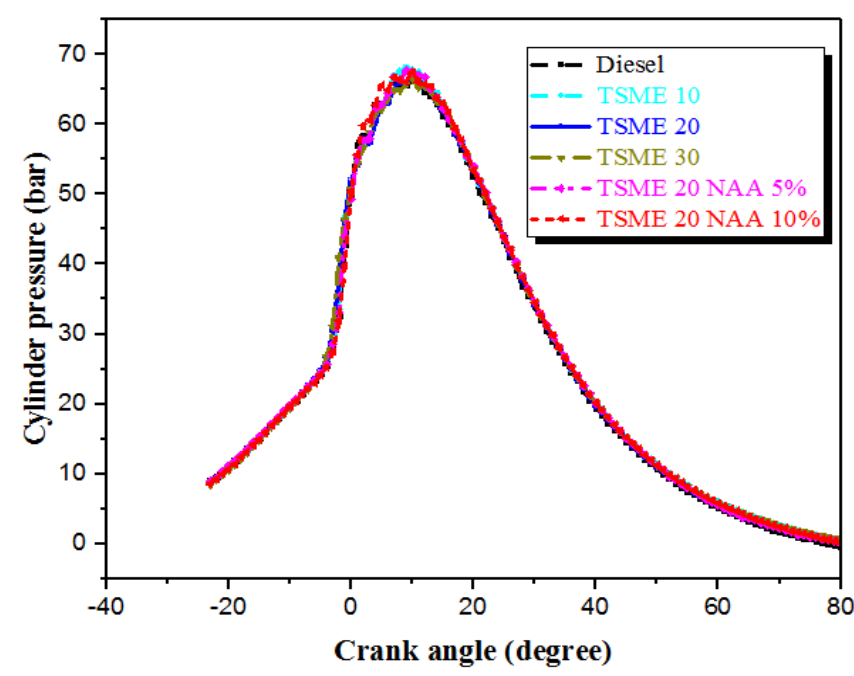

Figure 5. Variation of cylinder pressure with crank angle

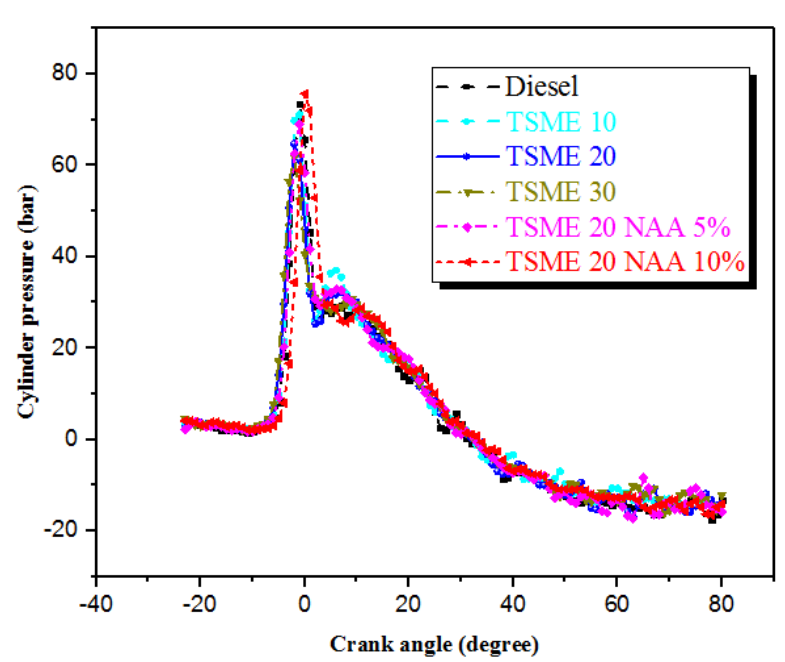

Figure 6. Heat release rate variation with crank angle

$$
\frac{d Q}{d \theta}=\left(\frac{\gamma}{\gamma}-1\right) P\left(\frac{d V}{d \theta}\right)+\left(\frac{1}{\gamma}-1\right) V(\mathrm{dP} / \mathrm{d} \theta)
$$

where $\frac{d Q}{d \theta}$ is heat release rate in $\mathrm{J} / \theta, P$ indicates the pressure inside the cylinder in Pascal, $\gamma$ denotes the adiabatic index, $V$ represents the volume of combustion space in $\mathrm{m}^{3}$.

\section{Cylinder pressure-crank angle diagram}

The cylinder pressure variation with respect to crank angle for the tested fuels of tamarind seed methyl ester and the base fuel at maximum load condition is shown in Figure 5. The rise of pressure in the cylinder mainly depends on mixing ability of fuel with air and also the nature of combustion phenomena. All tested fuels were followed the same nature of pressure variation at maximum load. The higher rate of pressure rise indicates the better burning ability of the $\mathrm{A} / \mathrm{F}$ mixture. It was observed that maximum gas pressure in the cylinder has occurred $9^{\circ}-11^{\circ}$ after TDC for the tested fuels and the maximum cylinder pressure was noticed for diesel, TSME 20 , TSME 20 NAA 5 and TSME 20 NAA 10 was 68.18 bar, 68.14 bar and 68.12 bar respectively and from this results, the maximum pressure rise found for TSME 20 biodiesel blend, which is 68.18 bar and it is slightly higher than diesel fuel.

\section{Cycle to cycle variation and Coefficient of variation (COV):}

The cylinder pressure data are considered over certain number of cycles at each crank angle in order to observe the effects of cycle variation on combustion characteristics. Cyclic variations can easily be seen from the above Figure 5 of cylinder pressure with respect to crank angle. Figure 5 indicates the cylinder pressure data for the tested fuels during compression, combustion/expansion strokes. It is observed that there is a marginal variation in cylinder pressure particularly during combustion periods. Coefficient of variation (COV) of cylinder pressure is used to investigate the cyclic variability. Coefficient of variation is the standard deviation of the cylinder pressure to the mean of the cylinder pressure and generally Coefficient of variation of cylinder maximum pressure expressed as

$$
\operatorname{COV}_{P_{\max }}=\frac{\sigma_{P_{\max }}}{P_{\max }} \times 100
$$

where $\sigma_{P_{\max }}$ is the standard deviation in $P_{\max }$ and $P_{\max }$ is the mean of the cylinder pressure.

The Coefficient of variation $(\mathrm{COV})$ is determined for diesel fuel operated compression ignition engine for 50 consecutive cycles and it is found as $\operatorname{COV}_{P_{\max }}=0.141$. This tendency shows that the increase in the number of cycles decreases the effects of cyclic variability on the averaged pressure data.

\section{Heat release rate}

Figure 6 shows the heat release rate variation of tested fuels with crank angle at maximum load condition of the diesel engine. It shown useful data related to the burning process of fuel in the combustion space and delay period. Heat release rate of tamarind seed methyl ester along with NAA additive blends and diesel fuel followed the same nature of heat generation during the period of combustion process was noticed in Figure 6 . The amount of heat generation for the TSME 20 NAA 10\% blend was marginally higher than the diesel fuel at maximum load condition and the maximum heat release rate occurred for tamarind seed methyl ester $20 \%$ with the $10 \%$ addition 


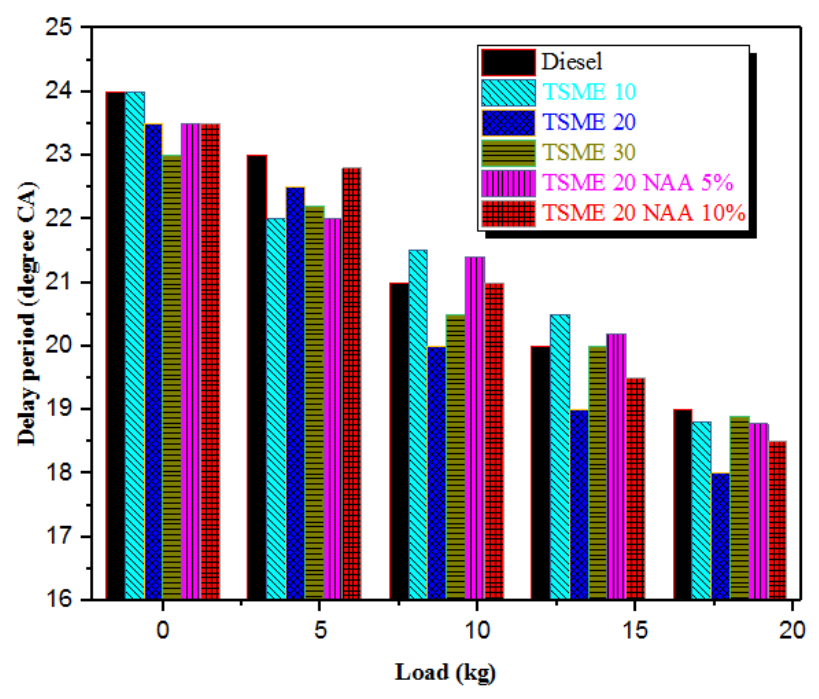

Figure 7. Ignition delay period variation with crank angle

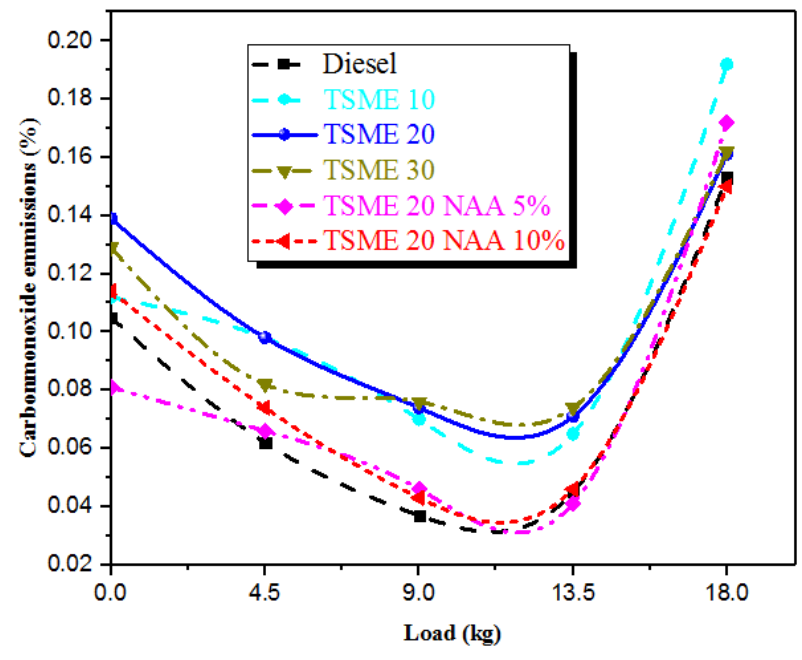

Figure 8. Carbon monoxide variation with engine load

of n-Amyl alcohol blend and It was found that $71.16 \mathrm{~kJ} /$ crank angle at $-1^{\circ}$ before TDC and it was $1.86 \%$ higher than diesel at maximum load condition. It is mainly attributed due to better mixing nature and more oxygen presence of NAA fuel additive. It was observed that the maximum heat release rate for all tested fuels occurred at $-1^{\circ}$ before TDC and the corresponding maximum heat release rate was obtained for diesel, TSME 20, TSME 20 NAA $5 \%$ and TSME 20 NAA $10 \%$.

\section{Delay petiod}

The variation of ignition delay period (IDP) at different engine loads for diesel, TSME blends and TSME 20 with $5 \%$ and $10 \%$ concentrations of NAA is presented in Figure 7 . The addition of n-amyl alcohol at different concentrations to the $20 \%$ tamarind seed methyl ester significantly decreases the delay period when compared to the diesel at all operating conditions. Due to enhanced fuel-air mixing and availability of inherent oxygen in the biodiesel and the NAA fuel additive results in reduction of delay period. The reduced in ignition delay period of TSME NAA 10\% biodiesel blend leads to an increase in the peak cylinder pressure in the combustion process. It is noticed that 20\% tamarind seed methyl ester biodiesel blend is shorter delay period than other tested fuels at all load conditions. The minimum ignition delay period for the TSME 20 blend is found to be $18^{\circ}$ crank angle.

\section{Emission Characteristics}

\section{Carbon monoxide emissions}

The carbon monoxide deviation with engine load for different tamarind seed biodiesel blends and diesel fuel is shown in Figure 8. It was mainly formed due to the incomplete combustion and also the CO formation depends on factors such as air-fuel ratio, injection pressure and fuel injection timing and the nature of the fuel. It was noticed that $\mathrm{CO}$ emissions of biodiesel blends and diesel followed the same trend with respect to increasing in load but the $\mathrm{CO}$ emissions were maximum at peak load condition due to incomplete combustion. When the additions of NAA at various concentrations to TSME 20 biodiesel blend, it was found that the formation of CO decreases with increase in load and least CO formed at full load. The CO formed for TSME 20 with NAA 5\% and $10 \%$ addition as $0.17 \%$, and $0.15 \%$ whereas for the diesel fuel at full load was $0.162 \%$. From the above Figure 8; the experimental results revealed that the addition of $\mathrm{n}$-Amyl alcohol to the biodiesel reduces the carbon monoxide formation with increasing the engine load and minimum at the full load condition.

\section{Hydrocarbon emissions}

The variation of hydrocarbons for diesel and tamarind biofuel blends with respect to engine load is shown in Figure 9. The hydrocarbon emissions for tested tamarind biodiesel fuels were lower over the diesel fuel in the entire load operation and also for the addition of n-Amyl alcohol, the hydrocarbon emissions were significantly decreased when compared with the diesel at full load. The HC emissions for the diesel and TSME biofuel blends $(10 \%, 20 \%$, and $30 \%)$ were $45 \mathrm{ppm}, 28 \mathrm{ppm}, 31 \mathrm{ppm}$ and $36 \mathrm{ppm}$ at maximum load condition. The minimum HC emission was found for TSME20 NAA $10 \%$ of $24 \mathrm{ppm}$ and there was a reduction of $46.6 \% \mathrm{HC}$ for this fuel additive blend over diesel fuel. This is due to inherent more oxygen presence in tamarind seed oil leads to better combustion. It was found that the HC emissions were increases with increase in blend concentration and HC formation was higher for TSME 30\% biodiesel blend. It was mainly due to higher viscosity and weak mixture 


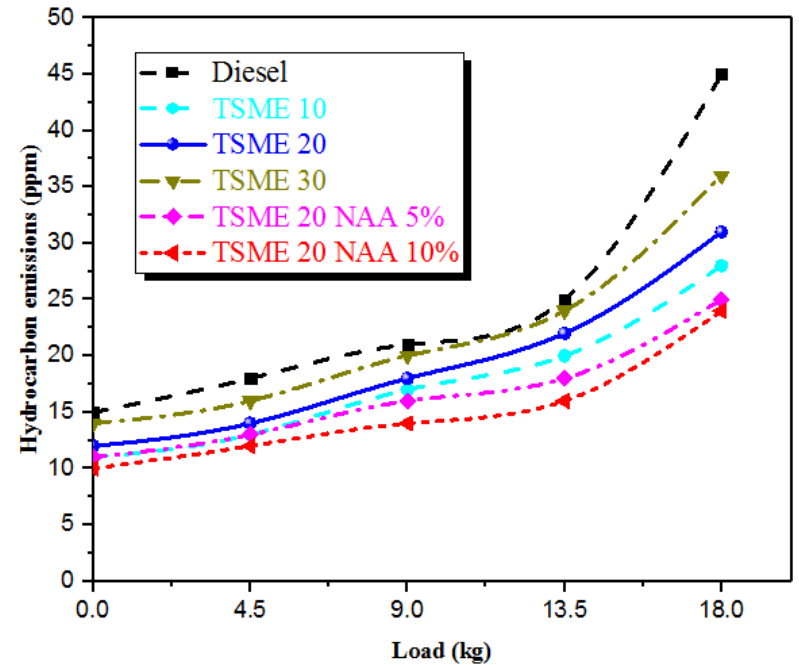

Figure 9. Hydrocarbons (HC) variation with engine load

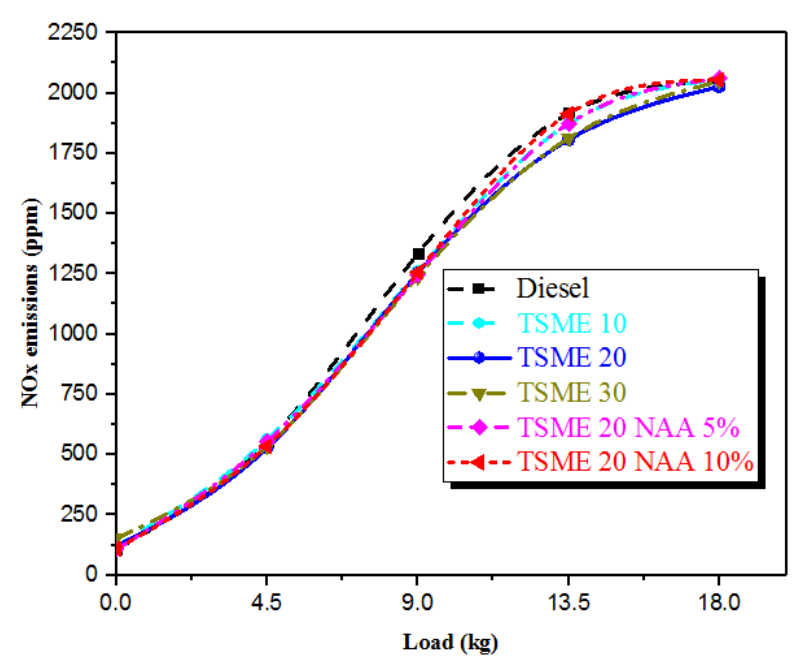

Figure 10. Nitrogen oxide $\left(\mathrm{NO}_{\mathrm{X}}\right)$ emissions variation with load

formation of diesel and the biodiesel. It was also noticed that the addition of NAA was reduced the HC formation at part load condition up to 75\% when compared with the biodiesel blends of TSME and also with diesel. From the below, it was concluded that significant reduction in $\mathrm{HC}$ emissions for the biodiesel blends with NAA addition when compared to the diesel fuel. Tamilselvan and Nalluswamy (2015) reported the use of pine oil biofuel blends on diesel engine characteristics results in lower emissions of HC at full load condition when compared to diesel.

\section{Nitrogen oxide emissions}

The nitrogen oxide mainly generated in diesel engine due to the presence of elevated temperature and accessibility of oxygen during the combustion process. The variation of nitrogen oxide $\left(\mathrm{NO}_{\mathrm{x}}\right)$ emissions of tamarind seed methyl ester and base fuel with respect to engine load is shown in Figure 10. The availability of oxygen and higher exhaust gas temperature in biodiesel blends produces the higher $\mathrm{NO}_{\mathrm{X}}$ formation. It was also found that the $\mathrm{NO}_{\mathrm{X}}$ level increases with increasing the engine load for all the experimentally tested fuels. The diesel engine rated capacity is $5.2 \mathrm{~kW}$. It was shown that $\mathrm{NO}_{\mathrm{X}}$ emissions were marginally lower for TSME20 biodiesel of $2026 \mathrm{ppm}$ as compared to diesel fuel of $2056 \mathrm{ppm}$. It was mainly attributed due to the low energy content of the tamarind seed oil. The addition of NAA for the TSME20 with concentration 5\% and 10\% increases the $\mathrm{NO}_{\mathrm{X}}$ emissions. The maximum NOX emissions were found with the TSME 20 NAA $10 \%$ at full load condition of 2109 ppm and it was $2.5 \%$ higher than the diesel fuel and it was also noticed that $\mathrm{NO}_{\mathrm{x}}$ formation for NAA added biodiesel blends were marginally higher than diesel. Similar results were reported by other researchers (Kumar et al., 2016; Singh, 2016). The higher $\mathrm{NO}_{\mathrm{x}}$ emissions generated by the TSME 20 biodiesel blend could be effectively reduced by the use of $10 \%$ exhaust gas recirculation approach reported by Dhana Raju and Kishore (2018).

\section{Smoke opacity}

The smoke opacity is a measure of soot content or soot concentration in the exhaust emissions. Figure 11 indicates the variation of soot concentration or smoke opacity for tested tamarind biodiesel blends and diesel fuel. The soot content of the exhaust gas was determined from the blackening of sample paper and the effective length. The smoke opacity was measured as the percentage. From the Figure 11, it is noticed that smoke opacity decreases for all biodiesel blends when compared to diesel at maximum load condition. The smoke concentration for the biodiesel blends (TSME 10, 20 and 30) were 59.3\%, 61.4\% 62.3\%, respectively and for diesel, it was 76.6\% at full load. The smoke opacity level for TSME 20 is $19.84 \%$ lesser than the diesel fuel at maximum load condition. The early start of combustion for biodiesel blends and advanced injection timing can further reduce the formation of smoke emission. The addition of small concentration of NAA to the TSME 20 blend, there was a significant reduction in smoke opacity when analyzed with biodiesel blends and the diesel fuel. 


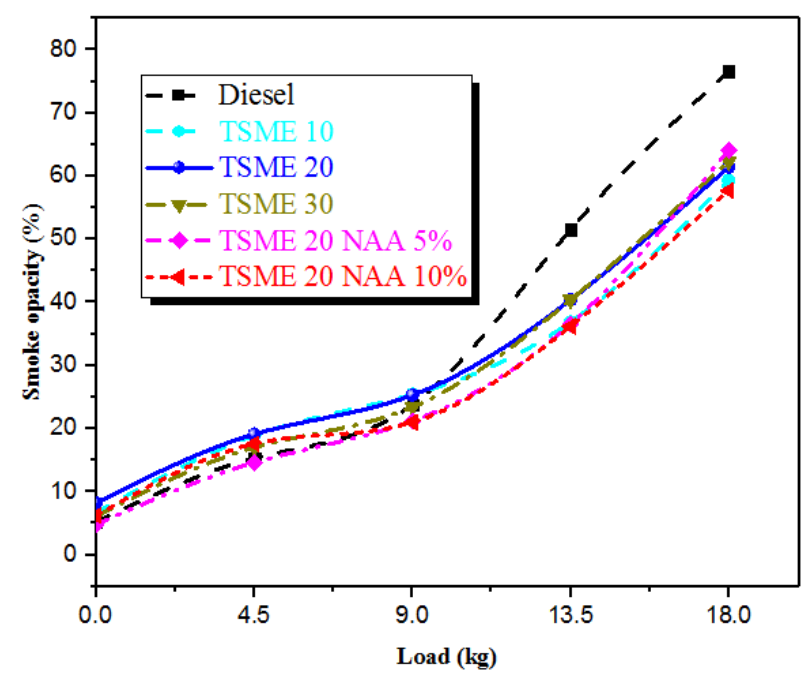

Figure 11. Smoke opacity (SO) variation with engine load

It was mainly due to higher volatility and oxygen enrichment provided by $n$-Amyl alcohol in enhancing the fuel evaporation and leads to better combustion. The smoke intensity of TSME 20 NAA 10 was $54.01 \%$ and it was $29.49 \%$ lower than the diesel fuel at the maximum load. Therefore small volumes of NAA addition to the TSME fuel could effectively reduce the smoke concentration.

\section{CONCLUSION}

In this experimental study, tamarind seed oil was considered as potential alternate fuel for diesel in compression ignition engine. The performance, combustion, and emission characteristics of tamarind seed biodiesel blends along with n-Amyl alcohol as an oxygenated fuel additive for TSME20 are evaluated and compared with base fuel. From the experimental outcomes, the following conclusions are drawn.

- The novel use of Tamarind seed methyl ester (TSME) is an important source of green fuel for the diesel engine towards the sustainability of energy and the environment.The TSME-NAA biodiesel blends shown improved engine characteristics when analyzed with diesel and also other blends of tamarind seed methyl ester.

- Among all the tested fuels, TSME 20 showed better performance and lower emission characteristics. The maximum brake thermal efficiency is $34.4 \%$ when compared to diesel of $34 \%$, which is $1.17 \%$ higher.

- The maximum heat release rate occurred for tamarind seed methyl ester $20 \%$ with the $10 \%$ addition of $n$ Amyl alcohol blend and It is found that $71.16 \mathrm{~kJ} / \mathrm{crank}$ angle at $-1^{\circ}$ before TDC and it is $1.86 \%$ higher than diesel at maximum load condition. It is also observed that maximum gas pressure in the cylinder has occurred $9^{\circ}-11^{\circ}$ after TDC for the tested fuels and the maximum cylinder pressure is found for TSME 20 biodiesel blend, which is 68.18 bar and it is slightly higher than diesel fuel

- The CO, HC, and Smoke opacity emissions are lower in the case of TSME and NAA blends than that diesel. However, the $\mathrm{NO}_{\mathrm{x}}$ emissions are higher for NAA blended fuel as compared to other blends and also with diesel.

- The addition of small concentration of NAA to the TSME 20 blend, there was a significant reduction in smoke opacity when analyzed with biodiesel blends and the diesel fuel. The smoke intensity of TSME 20 NAA $10 \%$ is $29.49 \%$ lower than the diesel fuel at the maximum load.

From the experimental findings, it is concluded that TSME 20 with NAA 10\% biodiesel blend gives better performance and lower emission characteristics when analyzed with diesel. Finally, the tamarind seed oil is a suitable and potential alternate fuel for replacing the diesel partially or completely in diesel engine towards the energy sustainability and eco-environment.

\section{NOMENCLATURE}

TSME- Tamarind seed methyl ester

BSFC - Brake Specific fuel Consumption

BTE - Brake Thermal Efficiency

$\mathrm{CO}$ - Carbon monoxide 
$\mathrm{NO}_{\mathrm{X}}$ - Nitrogen oxides

HC - Hydrocarbon

NAA- n-Amyl alcohol

kWh - Kilo Watt Hour

HRR - Heat release rate

TDC-Top dead center

CA-Crank angle

TSME 10 - 10\% Tamarind seed methyl ester $\& 90 \%$ diesel

TSME $20-20 \%$ Tamarind seed methyl ester \& $80 \%$ diesel

TSME 30- 30\% Tamarind seed methyl ester \& 70\% diesel

TSME 20 NAA 5\% -Tamarind seed methyl ester \& $80 \%$ diesel with n-amyl alcohol 5\%

TSME 20 NAA10\% - Tamarind seed methyl ester \& 80\% diesel with n-amyl alcohol 10\%

\section{REFERENCES}

Agarwal, D., Kumar, L. and Agarwal, A. K. (2008). Performance evaluation of a vegetable oil fuelled compression ignition engine. Renew. Energy, 33, 1147-1156. https://doi.org/10.1016/j.renene.2007.06.017

Ashok, B., Raj, R. T. K, Nanthagopal, K., Krishnan, R. and Subbarao, R. (2017). Lemon peel oil-A novel renewable alternative energy source for diesel engine. Energy Conversion and Management, 139, 110-121. https://doi.org/10.1016/j.enconman.2017.02.049

Ashok, B., Thundil Karuppa Raj, R., Nanthagopal, K., Krishnan, R. and Subbarao, R. (2017). Lemon peel oil - A novel renewable alternative energy source for diesel engine. Energy Conversion and Management, 139, 10-121. https://doi.org/10.1016/j.enconman.2017.02.049

Das, D., Pathak, V. and Upadhyaya, R. (2016). Evaluation of performance, emission and combustion characteristics of diesel engine fuelled with castor biodiesel. Biofuels, 7, 225-233.

Dhana Raju, V. and Kishore, P. S. (2017). Effect of fuel additives tamarind seed methyl ester biodiesel fuelled diesel engine. International Journal of Mechanical Engineering and Technology, 8, 958-968.

Dhana Raju, V. and Kishore, P. S. (2017). Investigation of green fuel design for low heat rejection diesel engine in sustaining the energy and environment. International conference on trends and advanced research in green energy technologies, ICTARGET.

Dhana Raju, V. and Kishore, P. S. (2018). Effect of exhaust gas recirculation on performance and emission characteristics of a diesel engine fuelled with tamarind biodiesel. International Journal of Ambient Energy. https:// doi.org/10.1080/01430750.2017.1421579

Dhana Raju, V., Kiran Kumar, K. and Kishore, P. S. (2016). Engine Performance and Emission characteristics of a Direct Injection Diesel Engine Fuelled with 1- Hexanol as a Fuel additive in Mahua Seed Oil Biodiesel Blends. Int. J. of Thermal \& Environmental Engineering, 13(2), 121-127. https:// doi.org/10.5383/ijtee.13.02.007

Dhanasekaran, R., Krishnamoorthy, V., Rana, D., Saravanan, S., Nagendran, A. and Kumar, B. R. (2017). A sustainable and eco-friendly fueling approach for direct-injection diesel engines using restaurant yellow grease and n-pentanol in blends with diesel fuel. Fuel, 193, 419-431. https:/ / doi.org/10.1016/j.fuel.2016.12.030

Heywood, J. B. (1984). Internal combustion engine fundamentals, USA: McGraw- Hill.

Imdadul, H. K., Rashed, M. M., Masjuki, H. H., Kalam, M. A., Kamruzzaman, M. and Rashedul, H. K. (2017). Quality improvement of biodiesel blends using different promising fuel additives to reduce fuel consumption and NO emission from CI engine. Energy Conversion \& Management, 138, 327-337. https://doi.org/10.1016/j.enconman.2017.01.077

Kadera, M. A., Islam, M. R., Parveen, M., Haniu, H. and Takai, K. (2013). Pyrolysis decomposition of tamarind seed for alternative fuel. Bio Resource Technology, 149, 1-7. https://doi.org/10.1016/j.biortech.2013.09.032

Kumar, B. R., Saravanan, S., Rana, D. and Nagendran. (2016a). A. Use of some advanced biofuels for overcoming smoke/NOx trade-off in a light-duty DI diesel engine. Renewable Energy, 96, 687-699. https://doi.org/10.1016/j.renene.2016.05.029

Kumar, R. S. and Loganathan, M. (2014). Combustion characteristics of the direct injection diesel engine fuelled with corn oil methyl ester. International Journal of Ambient Energy, 37, 136-142.

Kumar, R., Mishra, M. K., Singh, S. K. and Kumar, A. (2016b). Experimental evaluation of waste plastic oil and its blends on a single cylinder diesel engine. Journal of Mechanical Science and Technology, 30, 4781-4789. https:// doi.org/10.1007/s12206-016-0950-7

Li, L., Wang, J., Wang, Z. and Xiao J. (2015). Combustion and emission characteristics of diesel engine fuelled with diesel/biodiesel/pentanol fuel blends. Fuel, 156, 211-218. https://doi.org/10.1016/j.fuel.2015.04.048 
Moshin, R., Majid, Z. A., Shihnan, A. H., Nasri, N. S. and Sharer, Z. (2014). Effect of biodiesel on engine performance and exhaust emission for diesel dual fuel engine. Energy Conversion and Management, 88, 821-828. https://doi.org/10.1016/j.enconman.2014.09.027

Nagaraja, S., Prakash, K. S., Sudhakaran, R. and Kumar, M. S. (2016). Investigation on the emission quality, performance and combustion characteristics of the compression ignition engine fuelled with environmental friendly corn oil methyl ester - Diesel blends. Ecotoxicology and Environmental Safety, 132, 45-461.

Pali, H. S. and Kumar, N. (2016). Combustion, performance and emissions of Shorea robusta methyl ester blends in a diesel engine. Bio fuels, 7, 447-456. https://doi.org/10.1080/17597269.2016.1153363

Pali, H. S., Kumar, N. and Alhassan, Y. (2015). Performance and emission characteristics of an agricultural diesel engine fuelled with blends of Sal methyl esters and diesel. Energy Conversion and Management, 90, 146-153. https://doi.org/10.1016/j.enconman.2014.10.064

Shameer, P. M. and Ramesh, K. (2017). Green technology and performance consequences of an eco-friendly substance on a 4-stroke diesel engine at standard injection timing and compression ratio. Journal of Mechanical science and Technology, 31(3), 1497-1507. https://doi.org/10.1007/s12206-017-0249-3

Shelke, P. S., Sakhare, N. M. and Lahane, S. (2016). Investigation of Combustion Characteristics of a Cottonseed Biodiesel Fuelled Diesel Engine. Sciencedirect Procedia Technology, 25, 1049-1055. https:// doi.org/10.1016/j.protcy.2016.08.205

Singh, B. P. (2013). Performance and emission characteristics of conventional engine running on jatropha oil. Journal of Mechanical Science and Technology, 27, 2569-2574. https://doi.org/10.1007/s12206-013-0641-6

Tamilselvan, P. and Nalluswamy, N. (2015). Performance, combustion and emission characteristics of a compression ignition engine operating on pine oil. Biofuels, 6, 273-281. https://doi.org/10.1080/17597269.2015.1096152

Theansuwan, W. and Triratanasirichai, K. (2011). The biodiesel production from roast Thai sausage oil by transesterification reaction. American Journal of Engineering and Applied Science, 4, 130-132. https://doi.org/10.3844/ajeassp.2011.130.132

Wei, L., Cheung, C. S. and Huang, Z. (2014). Effect of n-pentanol addition on the combustion, performance and emission characteristics of a direct-injection diesel engine. Energy, 70, 172-180. https://doi.org/10.1016/j.energy.2014.03.106

Yamini, K., Dhana Raju, V. and Kishore, P. S. (2017). Experimental investigation on diesel engineusing DMC as a fuel additive tamarind seed oil methyl ester. International Research Journal of Engineering and Technology, 4, 13721379.

Yilmaz, N. and Atmanli, A. (2017). Experimental assessment of diesel engine fuelled with diesel- biodiesel-1pentanol blends. Fuel, 191, 190-197. https://doi.org/10.1016/j.fuel.2016.11.065 